\title{
COMO E POR QUE SOMOS FEMINISTAS
}

\author{
SIMONE PEREIRA SCHMIDT \\ Universidade Federal de Santa Catarina
}

\begin{abstract}
Resumo: Este artigo pretende debater a tarefa de uma publicação feminista hoje, no contexto cultural e político latino-americano e, mais especificamente, brasileiro. Tomando o caso da Revista Estudos Feministas como referência, este debate propõe uma reflexão sobre o que significa ser feminista dentro deste contexto. Assim, o feminismo será analisado como prática teórica norteadora de nossas iniciativas, desdobrando-se em seus papéis de campo teórico, prática interpretativa e lugar político.
\end{abstract}

Palavras-chave: publicações feministas; Brasil; América Latina; teoria feminista.

Ao pensar sobre' a tarefa de falar sobre o trabalho desenvolvido pela Revista Estudos Feministas, definindo seu lugar dentro deste debate, ocorreu-me começar problematizando o próprio tema proposto, ou seja: pensar nossa tarefa como publicação feminista e como se constitui nossa diferença em termos de um contexto cultural, ou, em outras palavras, que contexto cultural é este em que nos constituímos como feministas, e o que significa ser feminista para nós, neste contexto.

Um primeiro olhar para nossa revista identifica em seu próprio título uma tomada de posição: Estudos Feministas aponta para o desejo de fazer de uma publicação o lugar de tornar públicos (e portanto de fazer circular) os estudos (ou seja, uma determinada produção, de perfil marcadamente acadêmico) produzidos a partir de um ponto de vista específico, ou seja, o feminista. Assim, penso que o primeiro tema que deve tentar abordar é o do próprio conceito de feminismo. Estou entendendo o feminismo, em primeiro lugar, como uma arena, depois, como um campo teórico, uma prática interpretativa e, por fim, como um lugar político.

Se o feminismo, como prática política, já nasce como uma arena, lugar para onde confluem discursos vindos de muitos lugares, cena aberta de disputa e negociação de poder, com o visível alargamento do campo nas últimas décadas, esta sua característica se intensifica. E uma publicação que se pretende veiculadora e interlocutora desses debates deve, necessariamente, inserir-se nesta arena, para onde convergem os discursos de dentro e também de fora do espaço acadêmico, onde o político e o estético negociam sentidos, onde diferentes campos de saber reivindicam sua especificidade, e onde, enfim, vozes marcadas por diferenças geográficas, sexuais, étnicas, raciais, religiosas, geracionais, convivem, dialogam, disputam e se intersectam, acentuando-se reciprocamente, em variações que muitas vezes nos escapam. 
No campo teórico, acredito que tem sido nossa tarefa problematizar a dicotomia conceitual entre teoria e prática, constituindo nossos procedimentos como "práticas teóricas", em que nossa intervenção diária na arena das disputas de significado no campo do saber consiste em formular novas interpretações dos novos e velhos discursos produzidos na cultura. Um modo feminista de ler e interpretar o mundo, e de produzir discursos que interfiram nos contextos em que atuamos, parece ser a mais fundamental forma de luta política contemporânea. Esta nossa prática interpretativa e teórica deve constantemente rever e subverter lugares de poder, dentro e fora do feminismo.

Embora Elaine Showalter afirme, em "Feminismo e Literatura", que "“não existe uma narrativa-mãe a partir da qual se origine um decreto, e não há uma Sibila cujas lições o sustentem ou derrubem"', ${ }^{2}$ penso eu que, particularmente, para a crítica e a teoria feministas existe, sim, em nossa atuação presente, a sombra das matriarcas que fundaram um teto todo nosso, delimitando no campo da teoria uma casa construída como espaço de auto-representação e busca de autonomia. Os nomes dessas matriarcas são ainda constantemente evocados, e certamente cada um dos campos disciplinares ora presentes poderiam evocar os seus. No caso da literatura, que é minha casa mais restrita, eu convocaria Elaine Showalter, Susan Gubar, Sandra Gilbert, Anette Kolodny, Myra Jehlen, assinalando a sua inegável importância na delimitação de um território para as mulheres dentro da literatura e da tradição literária, que permitiu a realização de todo um fecundo trabalho de revisão do cânone, de releitura crítica da historiografia tradicional e de resgate de autoras e de obras.

O risco maior que em minha opinião decorre das lições das matriarcas reside na ameaça da claustrofobia que é própria dos guetos. Parece-me claro que a guetificação das propostas feministas se coloca sempre em nosso horizonte como um risco iminente, 0 que estava já sendo diagnosticado por Nina Auerbach no início dos anos 80:

As críticas feministas parecem particularmente relutantes em definir-se aos não-iniciados. Há um sentido no qual a nossa irmandade se tornou poderosa demais; como uma escola, nossa confiança em nós mesmas é tão potente que dispensamos a comunicação com as redes de poder e respeitabilidade que dizemos querer mudar. ${ }^{3}$

Podemos aqui evocar o que dizia outra das nossas matriarcas, a propósito de uma respeitável biblioteca cujas portas encontrou para si fechadas. "Se é desagradável ser impedida de entrar, é talvez pior ser impedida de sair", diz Virginia Woolf em Um teto todo $\mathrm{seu}^{4}$. Sua mesma constatação pode ser deslocada, da biblioteca dos patriarcas de Oxbridge, para a casa matriarcal das nossas precursoras teóricas feministas. Foi este movimento de saída que empreenderam as estudiosas que primeiramente nos propuseram o gênero como uma categoria de análise.

Assim o gênero, além de ser um instrumento "para reivindicar um certo terreno de definição, para insistir sobre a inadequação das teorias existentes em explicar as desigualdades persistentes entre as mulheres e os homens", ${ }^{5}$ conforme Joan Scott, é também um movimento de saída, de expansão das fronteiras da crítica feminista, cujos paradigmas já não davam conta das demandas colocadas pelos embates vividos tanto nos enfrentamentos teóricos quanto nas disputas políticas travadas pelas feministas.

O gênero é pois uma porta que se abre, de saída da casa matriarcal em direção ao mundo. Nessa saída, muito se ganhou e muito se perdeu.

Ganhamos o diálogo e a interação com outras identidades sociais, atuando em direção ao que Showalter apontou como uma possibilidade aberta para o feminismo contemporâneo: a construção, junto com outras posições radicais e de minorias, de uma "esquerda cultural". ${ }^{\circ}$ 
Paradoxalmente, contudo (e aqui retomamos a idéia defendida por Joan Scott de que os paradoxos são constitutivos da própria história do feminismo), essa abertura promovida pelo gênero tem resultado muitas vezes na neutralização do caráter mais "guerreiro" e contundente do feminismo, esvaziando-o de sua vinculação com uma história de lutas contra a subordinação das mulheres. História que é, afinal, o que de melhor temos, e talvez nossa única identidade.

Assim, as tendências recentes dos estudos de gênero, aliadas às contribuições das teorias pós-estruturalistas, que consideram a "mulher" um conceito vazio e essencialista, apontam para o risco de uma "celebração de um feminismo sem mulheres", como sugere Tânia Modleski. ${ }^{7}$

Para me auxiliar nesta reflexão sobre os riscos de sair e sobre os riscos de ficar nos limites da casa materna, gostaria de me remeter a $O$ Narrador, ${ }^{8}$ de Walter Benjamin. É conhecida a importância que o filósofo alemão atribui ao conceito de experiência neste texto. Na figura do narrador confluem dois tipos de experiência, igualmente importantes: a do viajante e a do camponês. Tanto qquele que muito chão percorreu como aquele que ficou preso à sua terra estão plenos de histórias, porque guardaram a experiência vivida como um tesouro raro, e generosamente a oferecem, em forma de narrativas partilhadas entre todos. Valem muito os dois narradores; Benjamin compara-os aos mestres e aos sábios, porque sair é aventurar-se no desconhecido, impregnar-se do novo que revitaliza o vivido, e ficar significa recolher o passado e impedir sua morte no esquecimento.

Tomo essa idéia como um mote para propor minha reflexão sobre o paradoxo de ficar/sair vivenciado pelas teorias feministas no presente.

Os riscos de sair são muitos, como vimos, inclusive aqueles que de algum modo implicam a perda de nossa identidade. Mas lá fora estão os outros: sujeitos, identidades, discursos... com quem devemos interagir, fazer alianças e coalizões. É condição de sobrevivência para o feminismo situar-se na zona de contato. Estou empregando aqui, evidentemente, o conceito de Mary Pratt, que se baseou na idéia das "linguagens de contato", oriunda da Lingüística. Tais linguagens improvisadas "se desenvolvem entre locutores de diferentes línguas nativas que precisam se comunicar entre si (...) usualmente no âmbito comercial". Essas linguagens são normalmente consideradas, assim como as sociedades em que se formam, "caóticas, bárbaras e amorfas". Assim, de forma sempre provisória e inaugural, e por isso mesmo cheia de possibilidades, a zona de contato constitui "uma tentativa de se invocar a presença espacial e temporal conjunta de sujeitos anteriormente separados por descontinuidades históricas e geográficas cujas trajetórias agora se cruzam". 9

O lugar fora da casa, a zona caótica dos muitos contatos é, portanto, o espaço vital em que nos lançamos em direção aos outros, abertas às muitas possibilidades, políticas, poéticas, de interação.

Por outro lado, creio que nos cabe também considerar a necessidade do retorno à casa de nossas matriarcas. Não como revisitação nostálgica do passado, mas como revisão crítica do presente, um modo de instaurar aquele passado-presente que, segundo Homi Bhabha, é um modo de "tocar o futuro em seu lado de cá" ${ }^{10}$. Reler este passado das teorias feministas significa uma tentativa de buscar, na radicalidade de suas propostas, a substância política que hoje por vezes falta à nossa prática teórica.Teresa de Lauretis sustenta que é crucial para o feminismo a afirmação de uma dupla força em direções contrárias: "a negatividade crítica de sua teoria e a positividade afirmativa de sua política"."11

Penso que se enfrentarmos nosso paradoxo entre o que está dentro da casa de nossas precursoras (a radicalidade afirmativa da categoria "mulher", por exemplo) e o que está fora, o mundo das infinitas diferenças e possibilidades, no espaço aberto e pleno de significados potenciais das zonas de contato que as múltiplas intersecções do 
gênero nos oferecem, poderemos, tal como o narrador de Walter Benjamin, oferecer, àqueles que nos cercam, e a todos que nos lêem, a riqueza de nossa experiência.

Enfim, falta ainda dizer alguma coisa sobre o feminismo como lugar político. Penso que este lugar só tem sentido hoje, em nossos contextos culturais e políticos, se for para constituir uma subversão radical, uma transgressão à própria noção do político. Ou seja, subverter as relações de fora e dentro do campo feminista, fora e dentro do acadêmico, fora e dentro do centro. Em outras palavras, acredito que devemos levar muito a sério aquilo que afirma Chandra Mohanty ${ }^{12}$, ao propor que a construção dos feminismos no Terceiro Mundo conjuga um empreendimento de desconstrução (a crítica interna aos feminismos hegemônicos ocidentais) e uma tarefa afirmativa (a formulação de estratégias e preocupações feministas autônomas, que sejam: geográfica, histórica e culturalmente situados. Construindo os feminismos fora do centro, embora em diálogo com ele, estamos estabelecendo redes alternativas, horizontais, que devem reorientar nossa prática, para fora do eixo centro-periferia. E isso vale tanto para os centros de fora como para os de dentro. Exemplo: lembro que, quando a REF se deslocou do Rio de Janeiro em direção a Santa Catarina, este movimento não deixou de causar certo espanto, alguma dúvida e talvez desconforto em muitos setores do movimento feminista e, principalmente, do feminismo acadêmico. De algum modo, o primeiro número aqui lançado foi recebido por todas com alegria, mas também com alívio: afinal, a Revista continuava sendo de qualidade! Algo que enviezadamente me lembra a desajeitada exclamação de nosso presidente, surpreso por se encontrar num certo país da África, diferente de tudo aquilo que seu imaginário concebia. Para sua surpresa, a África era maior e mais diversa do que imaginara. Alguns países nem pareciam pertencer à África. Pois me perdoem a ironia, mas me ocorre pensar que, para muitas de nós, nossos próprios trabalhos às vezes nem parecem ser do Brasil, e muito menos ainda, deste distante sul do Brasil. Não quero com esta lembrança fazer uma pura celebração da margem, mas retomar a idéia de redes através das quais possamos entrelaçar comunidades e histórias, discursos e práticas alternativas aos centros hegemônicos. Pois nossa formação apontou sempre na direção de uma única história, de certo modo linear e teleológica, e evidentemente etnocêntrica, do feminismo. Para ilustrar o que digo, gostaria de aqui acrescentar, à guisa de conclusão, um breve depoimento pessoal.

Minha formação como feminista, no início dos anos 80 , aconteceu em grande parte na definição de uma especificidade feminista que nos diferenciasse dos chamados "movimentos de mulheres", ou seja, aqueles movimentos de lutas populares protagonizados por mulheres, no país que então vivia seu renascimento democrático após o mais duro período da ditadura. Jovens intelectuais em formação, nós aprendemos desde cedo a cartilha da especificidade, palavra por meio da qual procurávamos nos definir, afastandonos daquelas que erguiam bandeiras sociais mais amplas, usando sua condição de mulheres para reivindicar o que, em nossa opinião, Ihes ditava a agenda da esquerda, historicamente masculina e patriarcal.

Foi necessário um longo percurso, em que por diversas vezes cruzei a fronteira que separa a teoria da ação política, num movimento de vai e vem que lembra os pontos de uma costura, foi necessário mesmo que houvesse essa costura em minha trajetória pessoal e política, para que eu chegasse hoje a compreender que, vivendo num contexto histórico diferente do europeu e do norte-americano, fui e sou parte de uma outra história do feminismo, nem sempre identificada com a modernidade, e sempre situada como periferia. Como parte dessa outra história localizada na América Latina, vi acontecer movimentos como o das margaridas na Paraíba, das sem-terra, das sem-teto; acompanhei as lutas de mulheres que foram às ruas para bater panelas contra a fome e a carestia, de mães que foram às praças gritar por seus filhos desaparecidos. Domésticas, donas de casa, negras, 
brancas, mestiças, cholas, indígenas, madres, guerrilheiras, margaridas, evitas, beneditas, a história do feminismo, por aqui, muitas vezes na contramão da pós-modernidade, se escreveu em sofridas lutas, onde a classe e a raça necessariamente se articulavam ao gênero, colocadas suas urgências todas na ordem do dia, antes mesmo de tal articulação imperar nas agendas dos feminismos metropolitanos.

Não há como, efetivamente, escrever a história do feminismo reivindicando uma especificidade construída a partir de fora da nossa experiência. Por isso talvez a tarefa mais urgente para a teoria feminista agora seja a de reler sua história a contrapelo, estabelecer uma zona de contato em que se ponham em diálogo a história do movimento de mulheres na América Latina e as teorias produzidas no espaço acadêmico, traduzidas (no sentido de tradução assinalado por Homi Bhabha como tarefa da crítica pós-colonial) dos grandes centros hegemônicos.

Uma rede de interações dessa natureza, penso que em grande parte ainda está por ser feita, em muitos campos de nossa prática teórica. E isso será efetivamente trabalhar nos espaços lacunares produzidos pela globalização, na construção de lugares outros, não centralizados, de saber e poder.

\section{Notas}

Copyright (c) 2004 by Revista Estudos Feministas.

' Esta é uma discussão que venho desenvolvendo há algum tempo, dentro de minha pesquisa, financiada pelo CNPq. Partes dela se encontram publicadas em outros lugares, como no artigo "Nas trilhas do tempo: anotações sobre o trânsito das teorias feministas no Brasil", in: BRANDÃO, Izabel e MUZART, Zahidé (orgs.) Refazendo nós: ensaios sobre mulher e literatura. Florianópolis/Santa Cruz do Sul: Mulheres/EDUNISC, 2003, p. 451-60 e na comunicação "Teorias feministas e suas 'ligações perigosas': do pós-moderno ao pós-colonial", apresentada no VIII Congresso Internacional da ABRALIC, Belo Horizonte, 2002.

2 Elaine SHOWALTER, 1990, p. 179-202.

${ }^{3}$ Apud SHOWALTER, 1994, p. 25.

${ }^{4}$ Virginia WOOLF, 1985, p. 19.

5 Joan SCOT, 1990, p. 13.

${ }^{6}$ SHOWALTER, 1990, p. 180.

${ }^{7}$ Apud Cláudia de Lima COSTA, 1998, p. 128.

${ }^{8}$ Walter BENJAMIN, 1992, p.27-57.

${ }^{9}$ Mary Louise PRATT, 1999, p.32.

${ }^{10}$ Homi BHABHA, 1998, p. 27.

11 Teresa de LAURETIS, 1994, p.238.

12 Chandra MOHANTY, 1997, p. 255-277.

\section{Referências}

BENJAMIN, Walter. "O narrador". In: BENJAMIN, Walter. Sobre arte, técnica, linguagem e política. Lisboa: Relógio D’Água, 1992. p.27-57.

BHABHA, Homi. O local da cultura. Belo Horizonte: Editora UFMG, 1998.

BRANDÃO, Izabel e MUZART, Zahidé (orgs.). Refazendo nós: ensaios sobre mulher e literatura. Florianópolis/Santa Cruz do Sul: Mulheres/EDUNISC, 2003.

COSTA, Cláudia de Lima. "O tráfico do gênero". Cadernos Pagu, n. 11, 1998, p. 127-140.

LAURETIS, Teresa de. "A tecnologia do gênero". In: HOLLANDA, Heloísa Buarque de (org.). Tendências e impasses: o feminismo como crítica da cultura. Rio de Janeiro: Rocco, 1994, p. 206-242.

MOHANTY, Chandra T. "Under western eyes: feminist scholarship and colonial discourses". In: MUFTI, Aamir; SHOHAT, Ella (eds.). Dangerous liaisons: gender, nation and postcolonial perspectives. Minneapolis: University of Minnnesota Press, 1997. p. 255-277. 
PRATT, Mary Louise. Os olhos do império: relatos de viagem e transculturação. Bauru: Edusc, 1999.

SCHMIDT, Simone Pereira. "Teorias feministas e suas 'ligações perigosas': do pós-moderno ao pós-colonial”. Comunicação apresentada no VIII Congresso Internacional da ABRALIC. Belo Horizonte, 2002.

SCHMIDT, Simone Pereira. "Nas trilhas do tempo: anotações sobre o trânsito das teorias feministas no Brasil". In: BRANDÃO, Izabel e MUZART, Zahidé (orgs.). Refazendo nós: ensaios sobre mulher e literatura. Florianópolis/Santa Cruz do Sul: Mulheres/EDUNISC, 2003. p. 451-60.

SCOTT, Joan. "Gênero, uma categoria útil de análise histórica". Educação e Realidade, v. 16, n. 2. Porto Alegre, p. 05-22, jul-dez. 1990.

SHOWALTER, Elaine. "A crítica feminista no território selvagem". In: HOLLANDA, Heloísa Buarque de (org.) Tendências e impasses: o feminismo como crítica da cultura.Rio de Janeiro, Rocco, 1994. p. 23-57.

SHOWALTER, Elaine. "Feminism and literature". In: COLLIER, Peter e GEYER-RYAN, Helga (eds.). Literary theory today. New York: Cornell University Press, 1990. p. 179-202.

WOOLF, Virginia. Um teto todo seu. Rio de Janeiro: Nova Fronteira, 1985.

\section{How and Why we Are Feminists}

Abstract: This article debates the role of contemporary feminist publications in the Latin-American and, more specifically, Brazilian political and cultural context. To do so, it examines one specific Brazilian feminist journal, Revista Estudos Feministas, to reflect upon the meanings of being a feminist today. It understands feminism as a theoretical practice informing women's daily activities and initiatives, as a hermeneutics and as a political location.

Keywords: feminist ; Brazil; Latin American; feminist theory. 